\title{
Surgery Prolongs the Survival of Patients with Metastatic, Recurrent, or Unresectable Locally Advanced Gastrointestinal Stromal Tumors Response to Imatinib Mesylate Treatment: A Systematic Review and Meta-analysis
}

Weihao Li

Sun Yat-sen University Cancer Center

Jianhong Peng

Sun Yat-sen University Cancer Center

Xinyue Li

Sun Yat-sen University Cancer Center

Rongxin Zhang

Sun Yat-sen University Cancer Center

Binyi Xiao

Sun Yat-sen University Cancer Center Jinghua Tang

Sun Yat-sen University Cancer Center

Desen Wan

Sun Yat-sen University Cancer Center

Zhizhong Pan

Sun Yat-sen University Cancer Center

Cong Li

Sun Yat-sen University Cancer Center

Xiaojun Wu ( $D$ wuxj@sysucc.org.cn )

Sun Yat-sen University Cancer Center

\section{Research Article}

Keywords: gastrointestinal stromal tumors, advanced, surgery, oncologic outcome, imatinib mesylate, meta-analysis

Posted Date: February 19th, 2021

DOl: https://doi.org/10.21203/rs.3.rs-212183/v1 
License: (c) (i) This work is licensed under a Creative Commons Attribution 4.0 International License. Read Full License 


\section{Abstract \\ Background}

The role of surgery in patients with metastatic, recurrent or unresectable locally advanced gastrointestinal stromal tumors (GIST) who respond to imatinib mesylate (IM) treatment is still not formally defined. Therefore, we systemically searched and analyzed the available literature to evaluate the oncologic benefits of surgery in this specific population.

\section{Methods}

A systematic literature search of the PubMed, Embase, and Cochrane Library databases was performed to identify relevant articles on July 16, 2020. Pooled data analysis was also performed using Review Manager.

\section{Results}

Totally 10 studies including 1188 patients (410 patients in the surgery group and 778 patients in the no surgery group) were included in the final analysis. No significant differences in baseline clinical characteristics were found except that patients in the surgery group were significantly younger (WMD, $-5.02,95 \% \mathrm{Cl},-8.38$ to $-1.67, P=0.003)$. In the overall population, pooled data showed a significant improvement in overall survival (OS) (HR, $0.62 ; 95 \% \mathrm{Cl}, 0.53$ to $0.73 ; P<0.0001)$ and progression-free survival (PFS) (HR, $0.57 ; 95 \% \mathrm{Cl}, 0.44$ to $0.72 ; P<0.0001)$ with surgery. In the subgroup analysis, the impact of surgery on patient response to IM treatment was further confirmed (OS: $\mathrm{HR}, 0.67 ; 95 \% \mathrm{Cl}, 0.55$ to $0.81 ; P<0.0001 ; \mathrm{PFS}: \mathrm{HR}, 0.62 ; 95 \% \mathrm{Cl}, 0.46$ to $0.82 ; P=0.009)$.

\section{Conclusions}

Surgery prolongs the OS and PFS of patients with metastatic, recurrent, or unresectable locally advanced GIST who respond to IM treatment. Future prospective, multicenter RCTs are warranted.

\section{Introduction}

Gastrointestinal stromal tumors (GIST) are the most common mesenchymal malignancies of the digestive tract, originating from the interstitial cells of Cajal. ${ }^{1}$ GIST compose approximately $20 \%$ of soft tissue sarcomas, and the annual incidence of these tumors is $11-20$ per million people. ${ }^{2,3}$ It is estimated that at the time of diagnosis, $15 \%-50 \%$ of patients develop metastatic disease. For patients with locally advanced GIST after undergoing complete resection, nearly $40 \%$ suffer recurrence within 2 years. ${ }^{4-6}$ Up to 
$90 \%$ of GIST have gain-of-function mutations in either KIT or platelet-derived growth factor receptor alpha (PDGFRA) receptor tyrosine kinases, with exon 11 of KIT being the most common mutation site. ${ }^{7,8}$

Since the introduction of imatinib mesylate (IM), a low-molecular tyrosine kinase inhibitor that blocks the kinase activity of both KIT and PDGFRA, the outcomes of patients with GIST have greatly improved. ${ }^{9,10} \mathrm{~A}$ 400-mg daily dosage of IM has become the first-line treatment for metastatic, recurrent or unresectable locally advanced GIST patients, achieving an objective response rate of approximately $80 \%$ and a median progression-free survival (PFS) of 33 months in responding patients. ${ }^{11,12}$ Although up to $80 \%$ of patients exhibit an initial response to IM treatment, ${ }^{13,14}$ some may eventually become resistant to IM, mainly due to the acquisition of second mutations, such as exons $13,14,17$ in KIT. ${ }^{15}$

The role of surgery in patients with advanced GIST is still not formally defined. In 2003, Heinrich and colleagues assumed that removing residual disease can extend the time of response by reducing the risk of acquiring secondary mutations in imatinib-sensitive patients. ${ }^{16}$ In recent decades, although several single-institution series ${ }^{17-23}$ have shown that surgery can be safely performed on metastatic or recurrent GIST patients in response to IM treatment, resulting in a better oncologic outcome, most of them were not comparative studies. Two randomized clinical trials (NCT00956072 in Europe and ChiCTR-TRC00000244 in China) failed to draw a firm conclusion regarding whether surgery prolongs the survival of patients in response to IM treatment because of failing to meet target accrual. Therefore, we systemically searched and analyzed the available literature to evaluate the oncologic benefits of surgery in patients with metastatic, recurrent, or unresectable locally advanced GIST who respond to IM treatment.

\section{Methods}

We performed a systematic review and meta-analysis of relevant comparative retrospective, prospective studies and randomized controlled trials according to the Preferred Reporting Items for Systematic Review and Meta-Analyses (PRISMA) guidelines.

\section{Study selection}

A systematic literature search of the PubMed, Embase, and Cochrane library databases was performed to identify relevant articles on July 16, 2020, with the following search terms: ("gastrointestinal stromal tumor*" OR “GIST*") AND ("surgery" OR “resection" OR "excision" OR "cytoreduction") AND ("recurrent" OR "metastatic" OR "advanced" OR "unresectable") AND ("imatinib mesylate" OR "imatinib"). Searches were limited to human studies and English-language publications. The reference lists of all retrieved studies and review articles were also searched manually. In the case of repeated studies by the same authors, the most recent or complete report was included.

\section{Inclusion and exclusion criteria}

The following inclusion criteria were used: (1) histologically confirmed CD117-positive, metastatic, recurrent, or unresectable locally advanced gastrointestinal stromal tumors; (2) treatment with 400 
mg/day IM (600-800 mg/day for patients with KIT exon 9 mutation) administered for at least 3 months and evaluated according to the Response Evaluation Criteria in Solid Tumors (RECIST); and (3) at least one of the oncologic outcomes (overall survival (OS) or PFS) mentioned in the main assessment results. OS was measured from the date of initiation of $400 \mathrm{mg} /$ day IM to the date of all-cause death. PFS was measured from the date of initiation of $400 \mathrm{mg} /$ day IM to the date of disease progression or tumor recurrence with $400 \mathrm{mg} /$ day IM or all-cause death with or without surgical intervention. Conference abstracts, reviews, letters, case reports, and noncomparative studies were excluded.

\section{Data extraction and quality assessment}

Data from the selected studies were extracted and summarized independently by two investigators (WH $\mathrm{Li}$ and $\mathrm{XY} \mathrm{Li}$ ), and any disagreements were discussed and resolved among all authors. The extracted data included basic information (first author, year of publication, study design, sample size, follow-up period, extension of disease, whether underwent surgery), clinicopathological characteristics (gender, age, tumor size, primary and metastatic tumor site, genotype of primary tumor, response to first-line imatinib, R0 resection rate), and oncologic outcomes (OS, PFS). If survival was not reported in the text, it was independently calculated from survival curves by two investigators (WH Li and JH Peng), or we contacted the corresponding authors via email to ask for relevant data.

The quality of all observational studies included was assessed with the Newcastle-Ottawa Scale (NOS) by examining three factors: method of patient selection, comparability of the study groups, and number of outcomes reported. A score of 0-9 was allocated to each study based on these three parameters. Studies achieving six or more stars were considered to be of high quality. One randomized controlled trial was considered to be of high quality for the purposes of this study.

\section{Statistical analysis}

All meta-analyses were performed using Review Manager 5.4 (Cochrane Collaboration, Oxford, UK). For continuous variables, we used the weight mean difference (WMD) to analyze and for dichotomous variables, we used the the odds ratio (OR) to analyze. Both of them were reported with $95 \%$ confidence intervals (Cls). If the results were expressed as medians with ranges, the standard deviations were calculated using the method described by Hozo and colleagues. ${ }^{24}$ The hazard ratio (HR) with a $95 \% \mathrm{Cl}$ was applied for comparison of the oncologic outcomes.

Heterogeneity between studies was assessed by the chi-square test and $R$ statistic, in which a $P$ value < 0.10 or $P>50 \%$ was defined as substantial heterogeneity. The random effects model was used if there was heterogeneity between studies; otherwise, the fixed effects model was used. Subgroup analyses were performed focusing on the patients who respond to IM treatment. Funnel plots were used to evaluate potential publication bias. Sensitivity analysis was performed to evaluate the robustness of our outcomes by removing low-quality studies. A two-tailed $P$ value less than 0.05 was considered significant if the $95 \% \mathrm{Cl}$ did not include the value 1 . 


\section{Results}

\section{Study selection and quality}

A total of 10 studies $^{25-34}$ including 1119 patients (361 patients in the surgery group and 758 patients in the no surgery group) met the eligibility criteria and were included in the final analysis (Figure 1). Manual searches of the references lists of the included studies did not yield any further studies. The quality of the included studies ranged from 3 to 7 on the NOS. The detailed quality assessment and scores for each study are provided in supplementary material Table S1.

\section{Patient characteristics}

The main features and demographic data of the studies included are shown in Table 1. Among these 10 studies, 7 studies were aimed at patient response to IM treatment, and the other 3 studies contained a small number of patients with progressive disease (PD). A total of 1089 patients (97.32\%) with good response (complete response or partial response) or stable disease and 30 patients (2.68\%) with PD were included in analysis, with an $\mathrm{R} 0$ resection rate ranging from $41.1 \%$ to $100 \%$.

Table 1. Summary of studies included

\begin{tabular}{|c|c|c|c|c|c|c|c|c|c|c|}
\hline \multirow[t]{2}{*}{ Study } & \multirow[t]{2}{*}{ Year } & \multirow[t]{2}{*}{ Design } & \multicolumn{2}{|c|}{$\begin{array}{l}\text { Sample } \\
(n)\end{array}$} & \multirow{2}{*}{$\begin{array}{l}\text { Extension } \\
\text { of } \\
\text { disease }^{a}\end{array}$} & \multirow{2}{*}{$\begin{array}{l}\text { Response to } \\
\text { first-line Imatinib } \\
(n, \mathrm{CR} / \mathrm{PR} / \mathrm{SD} / \mathrm{PD})\end{array}$} & \multirow[t]{2}{*}{$\begin{array}{l}\text { R0 resection } \\
\text { rate }(\%)\end{array}$} & \multicolumn{2}{|c|}{$\begin{array}{l}\text { Follow-up } \\
\text { (months) }\end{array}$} & \multirow[t]{2}{*}{ NOS } \\
\hline & & & $\mathrm{S}$ & NS & & & & S & NS & \\
\hline $\begin{array}{l}\text { Bauer et } \\
\text { al. }\end{array}$ & 2005 & $\mathrm{R}$ & 12 & 66 & 1 & $8 / 42 / 18 / 0$ & 91.7 & 29.8 & 25.7 & 5 \\
\hline $\begin{array}{l}\text { Blesius } \\
\text { et al. }\end{array}$ & 2011 & $\mathrm{P}$ & 9 & 16 & 3 & $0 / 15 / 7 / 3$ & 62.5 & 53.5 & 53.5 & 4 \\
\hline $\begin{array}{l}\text { Chang } \\
\text { et al. }\end{array}$ & 2015 & $\mathrm{R}$ & 76 & 106 & 1,2 & $20 / 110 / 29 / 23$ & 41.1 & 66.5 & 71.0 & 6 \\
\hline Du et al. & 2014 & RCT & 19 & 22 & 1,2 & $0 / 24 / 17 / 0$ & 73.7 & 23 & 49 & $\mathrm{RCT}$ \\
\hline $\begin{array}{l}\text { Kim et } \\
\text { al. }\end{array}$ & 2019 & $\mathrm{R}$ & 109 & 203 & 1,2 & $24 / 185 / 103 / 0$ & NA & 73.2 & 73.2 & 4 \\
\hline $\begin{array}{l}\text { Park et } \\
\text { al. }\end{array}$ & 2014 & $\mathrm{R}$ & 42 & 92 & 1,2 & $5 / 90 / 39 / 0$ & 62.0 & 58.9 & 58.9 & 7 \\
\hline $\begin{array}{l}\text { Rubió et } \\
\text { al. }\end{array}$ & 2015 & $\mathrm{R}$ & 27 & 144 & $1,2,3$ & $\mathrm{NA}^{\mathrm{c}}$ & 70.4 & 56.6 & 56.6 & 4 \\
\hline $\begin{array}{l}\text { Shen et } \\
\text { al. }\end{array}$ & 2015 & $\mathrm{R}$ & 10 & 15 & 1,3 & $0 / 25 / 0$ & 100.0 & 21.5 & 21.5 & 3 \\
\hline $\begin{array}{l}\text { Wang et } \\
\text { al. }\end{array}$ & 2020 & $\mathrm{R}$ & 36 & 15 & $1,2,3$ & $0 / 24 / 23 / 4$ & 84.4 & 43.7 & 43.7 & 6 \\
\hline $\begin{array}{l}\text { Xiao et } \\
\text { al. }\end{array}$ & 2018 & $\mathrm{R}$ & 21 & 79 & 1 & $4 / 48 / 48 / 0$ & 71.4 & 63.5 & 53.5 & 6 \\
\hline
\end{tabular}

Abbreviations: R, Retrospective study; P, Prospective cohort study; RCT, Randomized controlled trail; S, Surgery group; NS, No surgery group; CR, Complete response; PR, Partial response; SD, Stable disease; PD, Progressive disease; NOS, Newcastle-Ottawa Scale; NA, data not available. 
Notes: ${ }^{\mathrm{a}}$ Extension of disease: 1 = Metastasis, 2 = Local recurrence, 3 = Locally advanced initially unresectable.

$\mathrm{b}_{\text {Mean or median. }}$

${ }^{\mathrm{C}}$ This study focused on patients response to IM treatment without patient with progressive disease. However, detailed information is not available.

As shown in Table 2, patient clinical characteristics were compared between the surgery group and the no surgery group. Patients in the surgery group were significantly younger than patients in the no surgery group (WMD, $-5.02,95 \% \mathrm{Cl},-8.38$ to $-1.67, P=0.003$ ). There were no significant differences observed regarding gender, tumor size, primary and metastatic tumor site, genotype of primary tumor, or response to first-line imatinib between the two groups.

Table 2. Results of meta-analysis comparing clinical characteristics

\begin{tabular}{|c|c|c|c|c|c|c|c|}
\hline \multirow[t]{2}{*}{ Characteristics } & \multirow[t]{2}{*}{$\begin{array}{l}\text { Studies } \\
(n)\end{array}$} & \multicolumn{2}{|c|}{ No. of patients $(n)$} & \multirow{2}{*}{$\begin{array}{l}\text { WMD/OR } \\
(95 \% \mathrm{CI})\end{array}$} & \multirow[t]{2}{*}{$p$ value } & \multicolumn{2}{|c|}{$\begin{array}{l}\text { Study } \\
\text { heterogeneity }\end{array}$} \\
\hline & & $\mathrm{S}$ & NS & & & $I^{2}(\%)$ & $p$ value \\
\hline \multirow[t]{2}{*}{ Gender (male/female) } & 9 & $149 / 103$ & $366 / 203$ & 0.71 & 0.060 & 0 & 0.55 \\
\hline & & & & $\begin{array}{l}(0.51 \\
1.01)\end{array}$ & & & \\
\hline \multirow[t]{2}{*}{ Age $^{\mathrm{b}}$ (years) } & 7 & 54.44 & 59.45 & -5.02 & 0.003 & 75 & 0.0005 \\
\hline & & & & $\begin{array}{l}(-8.38, \\
-1.67)\end{array}$ & & & \\
\hline \multirow[t]{2}{*}{ Primary tumor size ${ }^{\mathrm{b}}(\mathrm{cm})$} & 3 & 5.47 & 4.85 & -0.31 & 0.240 & 0 & 0.93 \\
\hline & & & & $\begin{array}{l}(-0.84 \\
0.21)\end{array}$ & & & \\
\hline \multirow{2}{*}{$\begin{array}{l}\text { Primary tumor site (gastric/non- } \\
\text { gastric) }\end{array}$} & 9 & $78 / 174$ & $217 / 352$ & 0.73 & 0.060 & 0 & 0.89 \\
\hline & & & & $\begin{array}{l}(0.52, \\
1.02)\end{array}$ & & & \\
\hline \multirow{2}{*}{$\begin{array}{l}\text { Genotype of primary tumor } \\
\text { (KIT exon } 11 \text { mutation/Others) }\end{array}$} & 4 & $44 / 26$ & $131 / 60$ & 1.51 & 0.200 & 16 & 0.31 \\
\hline & & & & $\begin{array}{l}(0.81 \\
2.84)\end{array}$ & & & \\
\hline \multirow[t]{2}{*}{ Sites of metastasis (liver/Others) } & 4 & $92 / 59$ & $270 / 150$ & 0.78 & 0.720 & 86 & 0.0007 \\
\hline & & & & $\begin{array}{l}(0.19 \\
3.12)\end{array}$ & & & \\
\hline \multirow{2}{*}{$\begin{array}{l}\text { Response to first-line imatinib } \\
(\mathrm{CR}+\mathrm{PR} / \mathrm{SD}+\mathrm{PD})\end{array}$} & 7 & $136 / 36$ & $255 / 103$ & 1.26 & 0.630 & 77 & 0.0007 \\
\hline & & & & $\begin{array}{l}(0.49 \\
3.24)\end{array}$ & & & \\
\hline \multirow{2}{*}{$\begin{array}{l}\text { Response to first-line imatinib } \\
(\mathrm{CR}+\mathrm{PR} / \mathrm{SD})\end{array}$} & $5^{c}$ & $65 / 39$ & $181 / 93$ & 0.72 & 0.450 & 52 & 0.10 \\
\hline & & & & $\begin{array}{l}(0.31 \\
1.68)\end{array}$ & & & \\
\hline
\end{tabular}

Abbreviations: S, Surgery group; NS, No surgery group; WMD, Weighted mean difference; OR, Odds ratio; CI, Confidence interval; CR, Complete response; PR, Partial response; SD, Stable disease; PD, Progressive disease.

Notes: ${ }^{\mathrm{a}}$ Odds ratio. 
${ }^{\mathrm{b}}$ Mean age/tumor size.

${ }^{\mathrm{c}}$ Including studies involved in subgroup analysis.

\section{Oncologic outcomes}

In the overall population, pooled data showed a significant improvement in $\mathrm{OS}(\mathrm{HR}, 0.62 ; 95 \% \mathrm{Cl}, 0.53$ to $0.73 ; P<0.0001$; Figure 2A) and PFS (HR, $0.57 ; 95 \% \mathrm{Cl}, 0.44$ to $0.72 ; P<0.0001$; Figure $2 \mathrm{~B})$ after surgery compared with IM treatment alone.

\section{Subgroup analysis}

Subgroup analyses were performed to further investigate the impact of surgery on patients who respond to IM treatment. Studies that contain patients with PD were excluded. A total of 7 studies $25,28-32,34$ including 863 patients ( 240 patients in the surgery group and 621 patients in the no surgery group) were included in the subgroup analyses. Subgroup analysis results were consistent with the overall results (OS: $\mathrm{HR}, 0.67 ; 95 \% \mathrm{Cl}, 0.55$ to $0.81 ; P<0.0001$; Figure $3 \mathrm{~A}$; PFS: HR, $0.62 ; 95 \% \mathrm{Cl}, 0.46$ to $0.82 ; P=0.009$; Figure 3B).

\section{Sensitivity analysis and publication bias}

One randomized control trial ${ }^{28}$ and 4 retrospective studies ${ }^{27,30,33,34}$ with scores of six or higher on the NOS were included in the sensitivity analysis. The results related to OS and PFS did not changed significantly in the sensitivity analysis (shown in supplementary material Figure S1 and Figure S2).

As shown in Figure 4, a funnel plot was constructed for the studies included in this meta-analysis that reported OS. All studies lie inside the $95 \% \mathrm{Cls}$, with an even distribution around the vertical axis, indicating no obvious publication bias.

\section{Discussion}

In this meta-analysis, we investigated the oncologic outcomes of surgery for patients with metastatic, recurrent, or unresectable locally advanced GIST response to IM treatment. Our pooled data analyses and subgroup analyses showed that surgery prolongs the OS and PFS of patients in response to IM. In the sensitivity analysis of high-quality studies, there was no change in terms of the significance of OS and PFS. We found no significant differences in baseline clinical characteristics between the two groups except that patients in the surgery group were significantly younger. To our knowledge, this is the first meta-analysis to systematically compare the oncologic outcomes of surgery plus IM treatment with IM treatment alone in patients with metastatic, recurrent, or unresectable locally advanced GIST.

The potential benefit mechanism of surgery for patients with GIST after receiving IM treatment has been widely discussed. One of the most popular points of view is that surgery prolongs the effects of IM and prolongs survival time by removing residual disease before secondary resistance develops or by halting disease progression by eliminating resistant clones. ${ }^{16}$ On the other hand, the ultimate goal of treatment 
of unresectable locally advanced or metastatic patients through active multidisciplinary therapy (MDT) is to achieve status of no evidence of disease (NED), of which R0 resection surgical intervention is an essential part to achieve it. Without subsequent surgical treatment, tumor progression becomes inevitable because the effect of IM on these residual tumor cells is cytostatic rather than cytotoxic. ${ }^{7}$

Due to the natural limitation of selection bias, in previous retrospective studies, ${ }^{25,30}$ patients in the surgery group tended to have significantly better tolerance for traumatic treatment (patients were younger or had better performance status by the Eastern Cooperative Oncology Group criteria) and a higher rate of complete response or partial response. Additionally, a higher proportion of patients have primary lesions in the stomach, metastatic lesions in the liver and KIT exon 11 mutation genotype, meaning that more patients in the surgery group are at low risk. In the present meta-analysis, no significant differences in baseline clinical characteristics between the two groups were found except that patients in the surgery group were significantly younger, which means that the selection bias of retrospective studies included has been minimized, making the results more valuable and credible.

The role of surgery in patients with metastatic, recurrent, or unresectable locally advanced GIST has been widely examined, and there is a consensus that those who respond to IM treatment benefit more from surgery than those with PD. ${ }^{23,35-37}$ Obviously, due to the reduction of the operation difficulty and the scope of resection, patients with responsive disease (RD) will have a higher R0 resection rate than those with PD, which has been revealed to be associated with improved long-term survival. ${ }^{38,39} \mathrm{~A}$ multiinstitutional study by Bauer et al. ${ }^{39}$ found that patients with metastatic GIST treated with IM may benefit from surgery if complete resection can be achieved. Otherwise, surgery does not provide a survival benefit. In the present study, 30 patients $(2.68 \%)$ with PD were included in the overall population, which may affect the accuracy of the results, but it was considered to be slight and acceptable. After removing the studies that contain patients with PD in the subgroup analysis, the result that surgery provides a significant improvement in OS and PFS in patients with RD was further confirmed.

Several limitations should be acknowledged in the present meta-analysis. First, with only one RCT exception, all the studies included were observational and were carried out in different clinical centers with varying protocols and different levels of surgical expertise. Second, the limited sample size might weaken the accuracy and representativeness of our findings. The studies included in the analysis were mostly performed at tertiary cancer centers and major institutions, which might not reflect patient populations in the community. Third, statistical heterogeneity existed in some results, such as age, sites of metastasis, response to first-line imatinib and PFS. Calculations using the random effects model for overall incidence estimation might minimize but do not abolish this. Future systematic reviews should evaluate more subgroups or focus on specific groups, such as patients with liver metastasis, when enough literature is available. Although our study confirms the survival benefit of surgery in patients with metastatic, recurrent, or unresectable locally advanced GIST response to IM treatment, the findings must be validated in a prospective, multicenter clinical trial with a large population in the future. 


\section{Conclusion}

This meta-analysis indicates that surgery prolongs the OS and PFS of patients with metastatic, recurrent, or unresectable locally advanced GIST response to IM treatment. Future prospective, multicenter RCTS need to be undertaken to fully assess the role of surgery in patients with metastatic, recurrent, or unresectable locally advanced GIST and update the findings of this analysis.

\section{Abbreviations}

GIST, gastrointestinal stromal tumors; IM, imatinib mesylate; PFS, progression-free survival; OS, overall survival; NOS, Newcastle Ottawa Scale; WMD, weight mean difference; OR, odds ratio; Cls, confidence intervals; HR, hazard ratio; PD, progressive disease; MDT, multidisciplinary therapy; NED, no evidence of disease; RD, responsive disease.

\section{Declarations}

\section{Acknowledgments}

We deeply appreciate the help from all of our colleagues of the Department of Colorectal Surgery at Sun Yat-sen University Cancer Center who were involved in performing the treatments for the current study.

\section{Funding}

This study was funded by grants from the National Natural Science Foundation of China (no. 81772595 and no. 81871991).

\section{Availability of data and materials}

All data generated or analyzed during this study are included in this published article.

\section{Authors' contributions}

Study concept and design: WH Li, XJ Wu

Acquisition of data: WH Li, XY Li, JH Tang

Analysis and interpretation of data: JH Peng, RX Zhang, BY Xiao

Drafting of the manuscript: WH Li, JH Peng, C Li

Review and approval of the final manuscript: All authors

Supervision: DS Wan, ZZ Pan, XJ Wu 


\section{Ethics approval and consent to participate}

All analyses were based on previously published studies; thus, no ethical approval or patient consent were required.

\section{Consent for publication}

Not applicable.

\section{Competing interests}

The authors declare that they have no competing interests.

\section{References}

1. Miettinen M, Lasota J, Sobin LH. Gastrointestinal stromal tumors of the stomach in children and young adults: a clinicopathologic, immunohistochemical, and molecular genetic study of 44 cases with long-term follow-up and review of the literature. Am J Surg Pathol 2005;29:1373-1381.

2. Joensuu H, Hohenberger P, Corless CL. Gastrointestinal stromal tumour. Lancet 2013;382:973-983.

3. von Mehren M, Joensuu H. Gastrointestinal Stromal Tumors. J Clin Oncol 2018;36:136-143.

4. Dematteo RP, Ballman KV, Antonescu CR, et al. Adjuvant imatinib mesylate after resection of localised, primary gastrointestinal stromal tumour: a randomised, double-blind, placebo-controlled trial. Lancet 2009;373:1097-1104.

5. DeMatteo RP, Lewis JJ, Leung D, et al. Two hundred gastrointestinal stromal tumors: recurrence patterns and prognostic factors for survival. Ann Surg 2000;231:51-58.

6. Nilsson B, Bümming P, Meis-Kindblom JM, et al. Gastrointestinal stromal tumors: the incidence, prevalence, clinical course, and prognostication in the preimatinib mesylate era-a population-based study in western Sweden. Cancer 2005;103:821-829.

7. Rubin BP, Singer S, Tsao C, et al. KIT activation is a ubiquitous feature of gastrointestinal stromal tumors. Cancer Res 2001;61:8118-8121.

8. Heinrich MC, Corless CL, Duensing A, et al. PDGFRA activating mutations in gastrointestinal stromal tumors. Science 2003;299:708-710.

9. Plaat BE, Hollema H, Molenaar WM, et al. Soft tissue leiomyosarcomas and malignant gastrointestinal stromal tumors: differences in clinical outcome and expression of multidrug resistance proteins. J Clin Oncol 2000;18:3211-3220.

10. Buchdunger E, Cioffi CL, Law N, et al. Abl protein-tyrosine kinase inhibitor STI571 inhibits in vitro signal transduction mediated by c-kit and platelet-derived growth factor receptors. J Pharmacol Exp Ther 2000;295:139-145.

11. Heinrich MC, Corless CL, Blanke CD, et al. Molecular correlates of imatinib resistance in gastrointestinal stromal tumors. J Clin Oncol 2006;24:4764-4774. 
12. Blanke CD, Rankin C, Demetri GD, et al. Phase III randomized, intergroup trial assessing imatinib mesylate at two dose levels in patients with unresectable or metastatic gastrointestinal stromal tumors expressing the kit receptor tyrosine kinase: S0033. J Clin Oncol 2008;26:626-632.

13. Blanke $C D$, Demetri GD, von Mehren $M$, et al. Long-term results from a randomized phase II trial of standard- versus higher-dose imatinib mesylate for patients with unresectable or metastatic gastrointestinal stromal tumors expressing KIT. J Clin Oncol 2008;26:620-625.

14. Verweij J, Casali PG, Zalcberg J, et al. Progression-free survival in gastrointestinal stromal tumours with high-dose imatinib: randomised trial. Lancet 2004;364:1127-1134.

15. von Mehren M. Imatinib-refractory gastrointestinal stromal tumors: the clinical problem and therapeutic strategies. Curr Oncol Rep 2006;8:192-197.

16. Heinrich MC, Corless CL, Demetri GD, et al. Kinase mutations and imatinib response in patients with metastatic gastrointestinal stromal tumor. J Clin Oncol 2003;21:4342-4349.

17. Tielen $R$, Verhoef $C$, van Coevorden $F$, et al. Surgery after treatment with imatinib and/or sunitinib in patients with metastasized gastrointestinal stromal tumors: Is it worthwhile? World Journal of Surgical Oncology 2012;10.

18. Bonvalot $\mathrm{S}$, Eldweny $\mathrm{H}$, Péchoux $\mathrm{CL}$, et al. Impact of surgery on advanced gastrointestinal stromal tumors (GIST) in the imatinib era. Ann Surg Oncol 2006;13:1596-1603.

19. Andtbacka RH, $\mathrm{Ng}$ CS, Scaife CL, et al. Surgical resection of gastrointestinal stromal tumors after treatment with imatinib. Ann Surg Oncol 2007;14:14-24.

20. Raut CP, Posner M, Desai J, et al. Surgical management of advanced gastrointestinal stromal tumors after treatment with targeted systemic therapy using kinase inhibitors. J Clin Oncol 2006;24:23252331.

21. Rutkowski P, Nowecki Z, Nyckowski P, et al. Surgical treatment of patients with initially inoperable and/or metastatic gastrointestinal stromal tumors (GIST) during therapy with imatinib mesylate. $J$ Surg Oncol 2006;93:304-311.

22. Mussi C, Ronellenfitsch U, Jakob J, et al. Post-imatinib surgery in advanced/metastatic GIST: is it worthwhile in all patients? Ann Oncol 2010;21:403-408.

23. Gronchi A, Fiore M, Miselli F, et al. Surgery of residual disease following molecular-targeted therapy with imatinib mesylate in advanced/metastatic GIST. Ann Surg 2007;245:341-346.

24. Hozo SP, Djulbegovic B, Hozo I. Estimating the mean and variance from the median, range, and the size of a sample. BMC Med Res Methodol 2005;5:13.

25. Bauer S, Hartmann JT, de Wit M, et al. Resection of residual disease in patients with metastatic gastrointestinal stromal tumors responding to treatment with imatinib. International journal of cancer 2005;117:316-325.

26. Blesius A, Cassier PA, Bertucci F, et al. Neoadjuvant imatinib in patients with locally advanced non metastatic GIST in the prospective BFR14 trial. BMC cancer 2011;11:72. 
27. Chang SC, Liao CH, Wang SY, et al. Feasibility and Timing of Cytoreduction Surgery in Advanced (Metastatic or Recurrent) Gastrointestinal Stromal Tumors During the Era of Imatinib. Medicine (Baltimore) 2015;94:e1014.

28. Du CY, Zhou Y, Song C, et al. Is there a role of surgery in patients with recurrent or metastatic gastrointestinal stromal tumours responding to imatinib: a prospective randomised trial in China. Eur J Cancer 2014;50:1772-1778.

29. Kim JH, Ryu MH, Yoo C, et al. Long-term survival outcome with tyrosine kinase inhibitors and surgical intervention in patients with metastatic or recurrent gastrointestinal stromal tumors: A 14-year, singlecenter experience. Cancer Med 2019;8:1034-1043.

30. Park SJ, Ryu MH, Ryoo BY, et al. The role of surgical resection following imatinib treatment in patients with recurrent or metastatic gastrointestinal stromal tumors: results of propensity score analyses. Ann Surg Oncol 2014;21:4211-4217.

31. Rubió-Casadevall J, Martinez-Trufero J, Garcia-Albeniz X, et al. Role of surgery in patients with recurrent, metastatic, or unresectable locally advanced gastrointestinal stromal tumors sensitive to imatinib: a retrospective analysis of the Spanish Group for Research on Sarcoma (GEIS). Ann Surg Oncol 2015;22:2948-2957.

32. Shen $\mathrm{C}$, Chen $\mathrm{H}$, Yin $\mathrm{Y}$, et al. Treatment and Prognoses in Patients With Primary Gastrointestinal Stromal Tumors $\geq 10+\nabla \mathrm{cm}$ : A Single-Institution Experience in China. Medicine (Baltimore) 2015;94:e1117.

33. Wang J, Yin Y, Shen C, et al. Preoperative imatinib treatment in patients with locally advanced and metastatic/recurrent gastrointestinal stromal tumors: A single-center analysis. Medicine (United States) 2020;99.

34. Xiao B, Peng J, Tang J, et al. Liver surgery prolongs the survival of patients with gastrointestinal stromal tumor liver metastasis: a retrospective study from a single center. Cancer Manag Res 2018;10:6121-6127.

35. Yeh CN, Chen TW, Tseng JH, et al. Surgical management in metastatic gastrointestinal stromal tumor (GIST) patients after imatinib mesylate treatment. J Surg Oncol 2010;102:599-603.

36. Sym SJ, Ryu MH, Lee JL, et al. Surgical intervention following imatinib treatment in patients with advanced gastrointestinal stromal tumors (GISTs). J Surg Oncol 2008;98:27-33.

37. Qiu H, Zhou Z, Feng X, et al. Results of long-term follow-up for patients with advanced gastrointestinal stromal tumor underwent palliative surgery after tyrosine kinase inhibitors therapy. Journal of Clinical Oncology 2016;34.

38. Cananzi FC, Belgaumkar A, Lorenzi B, et al. Liver surgery in the multidisciplinary management of gastrointestinal stromal tumour. ANZ J Surg 2014;84:937-942.

39. Bauer S, Rutkowski P, Hohenberger P, et al. Long-term follow-up of patients with GIST undergoing metastasectomy in the era of imatinib -- analysis of prognostic factors (EORTC-STBSG collaborative study). Eur J Surg Oncol 2014;40:412-419. 
Figures

\section{PubMed: $n=254$}

$$
\text { Embase: } n=544
$$

\section{Cochrane: $n=65$}

Duplications : $n=143$

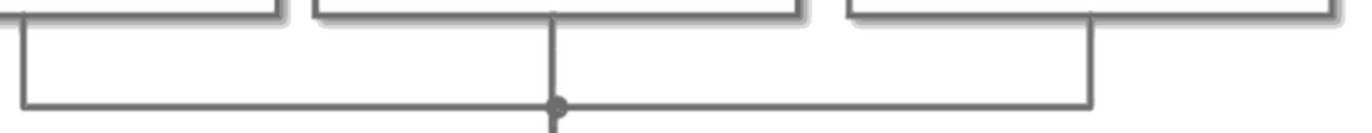

\section{Titles and abstracts screened:}

$$
n=720
$$

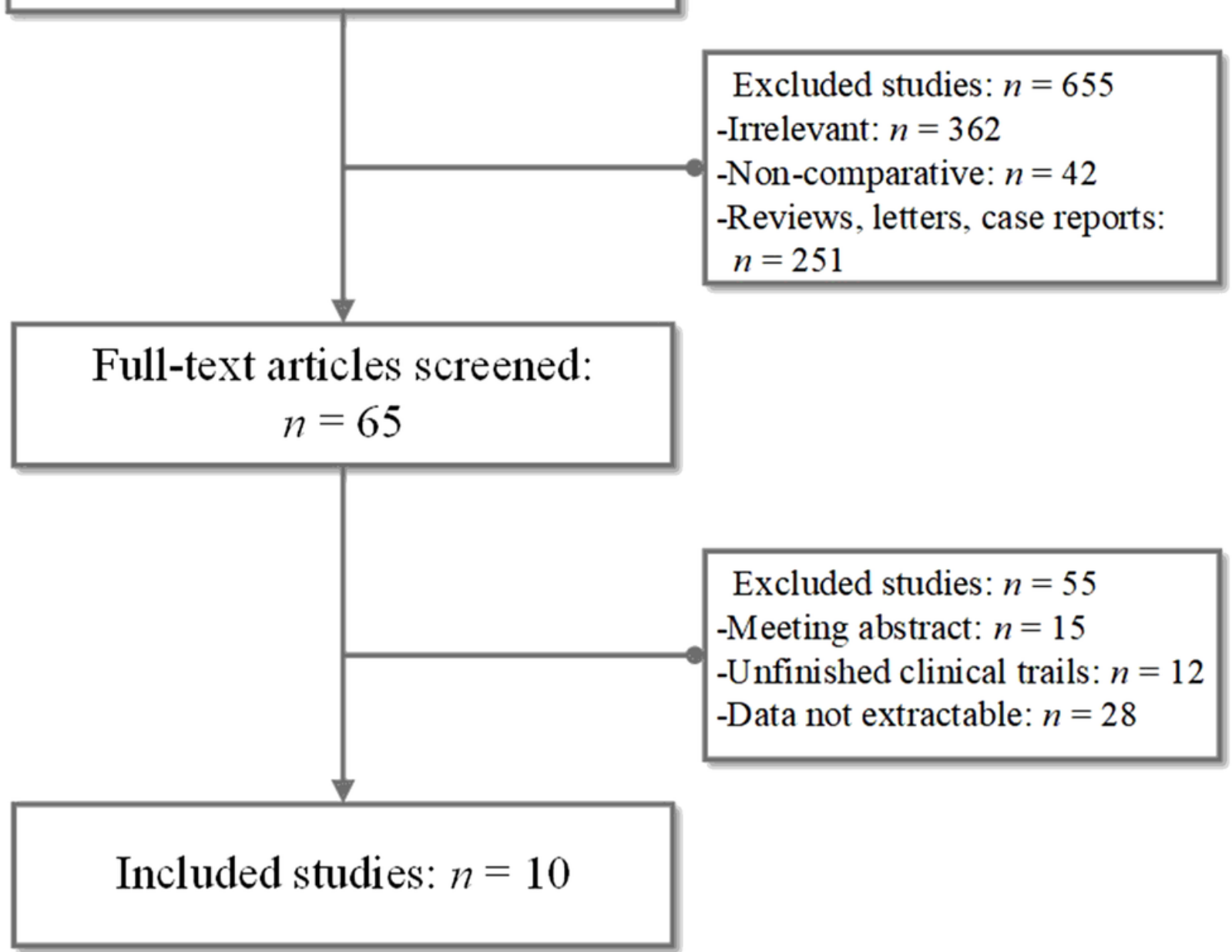

\section{Figure 1}

Flowchart of study selection. 


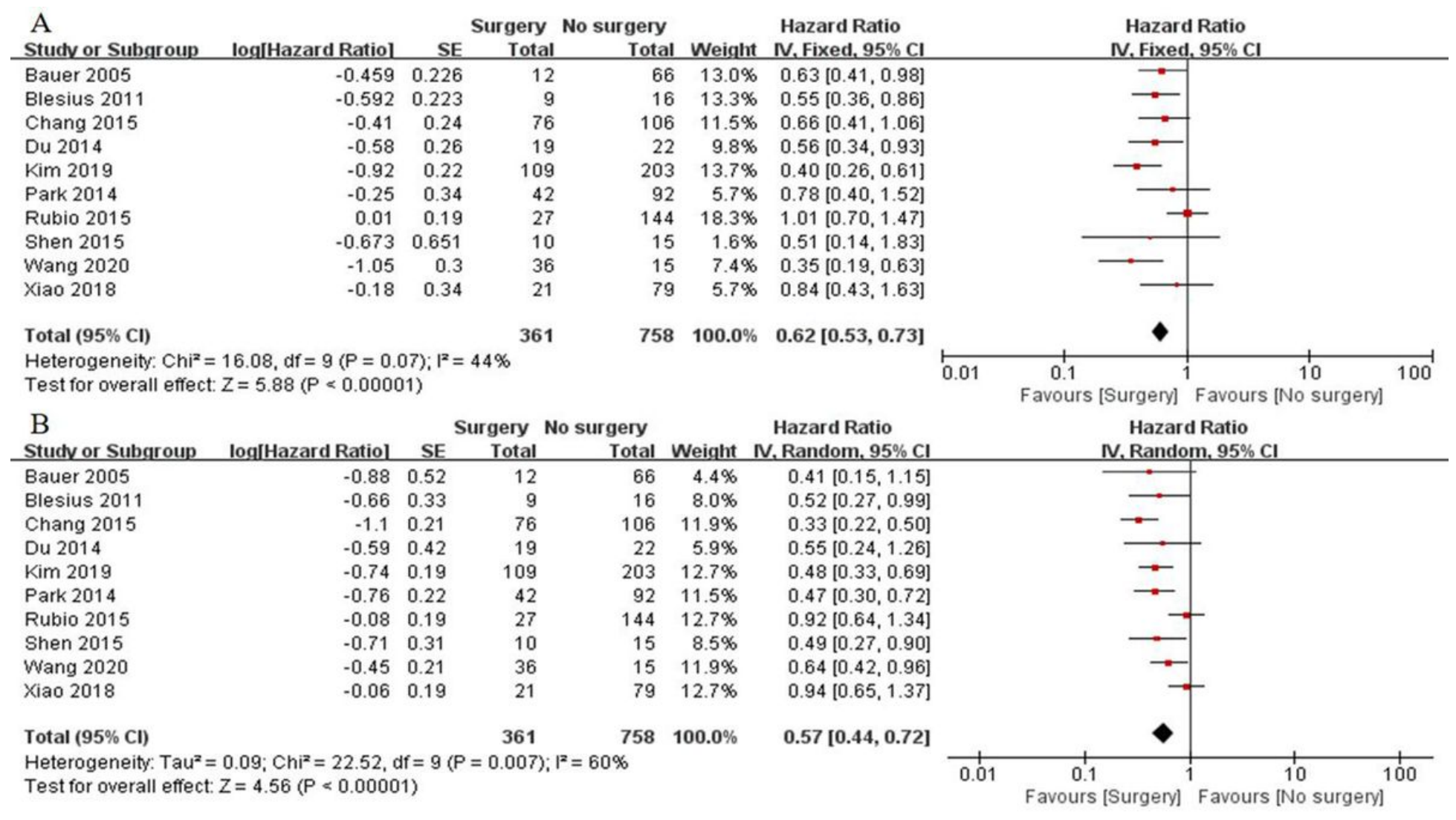

\section{Figure 2}

Forest plot and meta-analysis of oncologic outcomes. A: Overall survival; B: Progression-free survival.

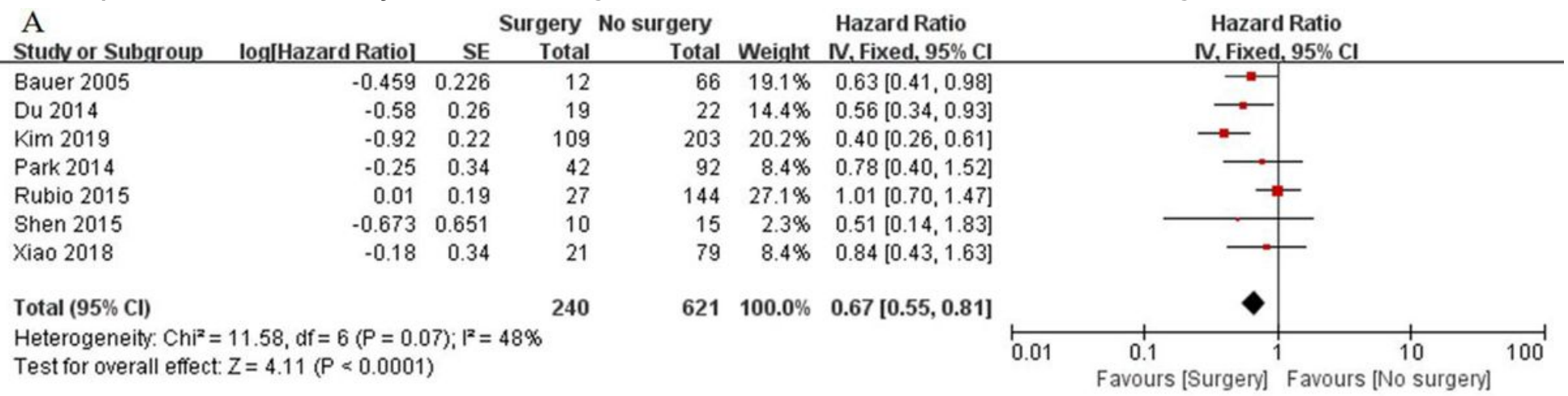

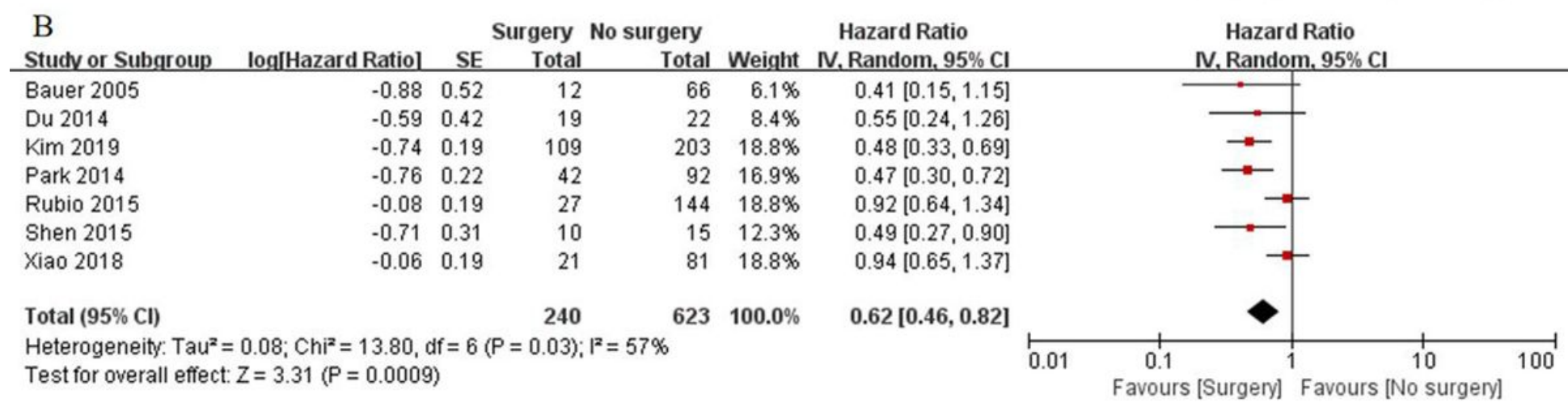


Forest plot and meta-analysis of oncologic outcomes of patients who respond to imatinib. A: Overall survival; B: Progression-free survival.

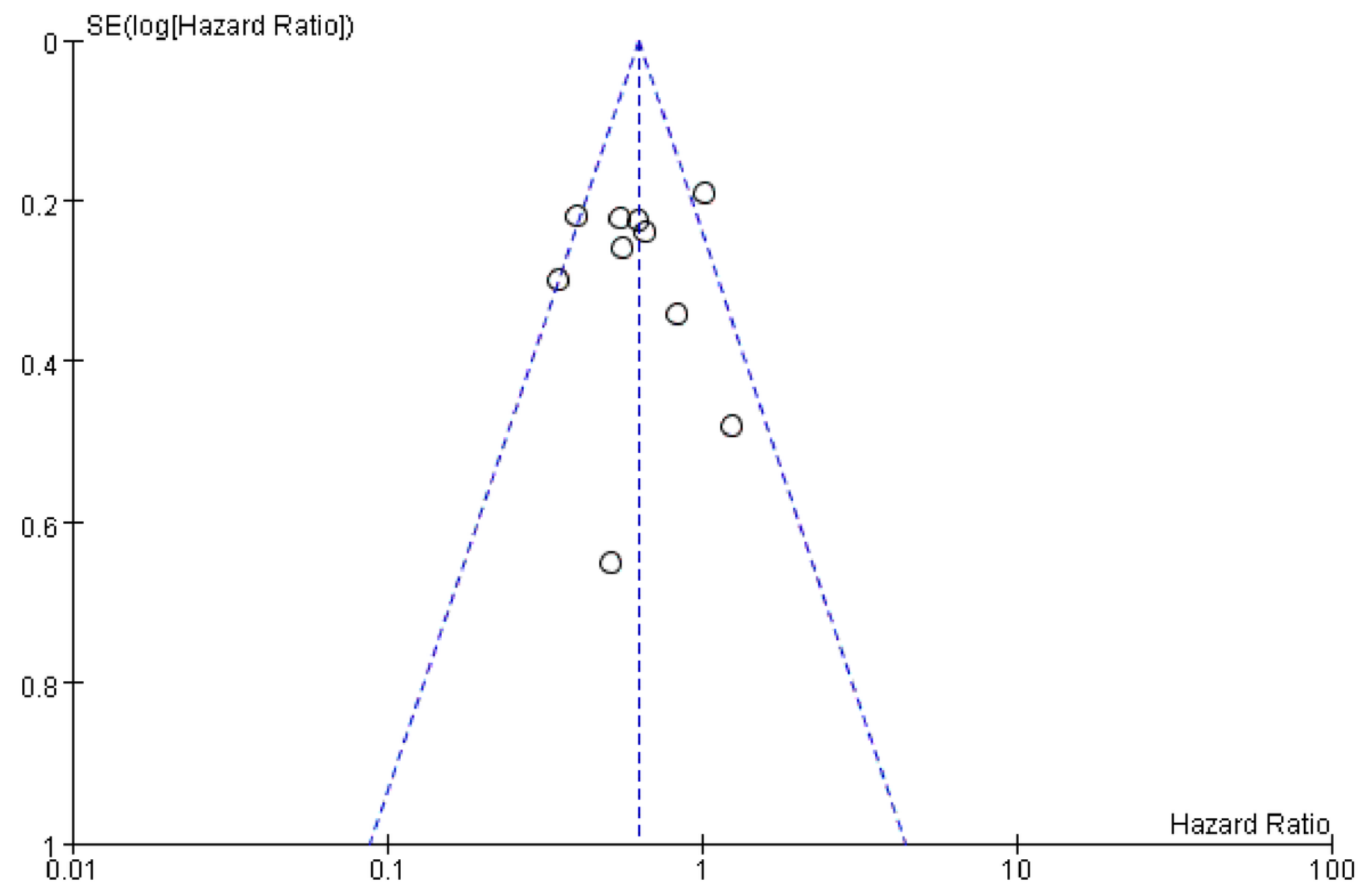

\section{Figure 4}

Funnel plots illustrating the meta-analysis of overall survival. SE = standard error; $\mathrm{HR}=$ hazard ratio.

\section{Supplementary Files}

This is a list of supplementary files associated with this preprint. Click to download.

- FigureS1.tif

- Figures2.tif

- TableS1.docx

- PRISMAChecklistMSWord.doc 